Article

\title{
Exogenous Melatonin Improves Salt Tolerance by Mitigating Osmotic, Ion, and Oxidative Stresses in Maize Seedlings
}

\author{
Jianhong Ren ${ }^{1,2,+}$, Jun Ye ${ }^{3,4,5,+}$, Lina Yin ${ }^{2,5}$, Gouxia Li ${ }^{2,5}$, Xiping Deng ${ }^{1,2,5}$ and \\ Shiwen Wang $2,5, *$ (D)
}

1 State Key Laboratory of Soil Erosion and Dryland Farming on the Loess Plateau, College of Life Sciences, Northwest A\&F University, Yangling 712100, China; renjh@nwafu.edu.cn (J.R.);

dengxp@ms.iswc.ac.cn (X.D.)

2 State Key Laboratory of Soil Erosion and Dryland Farming on the Loess Plateau, Institute of Soil and Water Conservation, Northwest A\&F University, Yangling 712100, China; linayin@nwsuaf.edu.cn (L.Y.); ligx@ms.iswc.ac.cn (G.L.)

3 Institute of Crop Breeding and Cultivation, Inner Mongolia Academy of Agricultural \& Animal Husbandry Sciences, Hohhot 010031, China; yejun@imaaahs.ac.cn

4 College of Agronomy, Hebei Agricultural University, Baoding 071001, China

5 Institute of Soil and Water Conservation, Chinese Academy of Sciences and Ministry of Water Resources, Yangling 712100, China

* Correspondence: shiwenwang@nwsuaf.edu.cn; Tel.: +86-29-87012872

$\dagger$ Equal contribution.

Received: 31 March 2020; Accepted: 4 May 2020; Published: 8 May 2020

check for updates

\begin{abstract}
Melatonin has been confirmed extensively for the positive effects on increasing plant tolerance to various abiotic stresses. However, the roles of melatonin in mediating different stresses still need to be explored in different plants species and growth periods. To investigate the role of melatonin in mitigating salt stress, maize (Zea mays L.) seedlings growing in hydroponic solution were treated with $100 \mathrm{mM} \mathrm{NaCl}$ combined with or without $1 \mu \mathrm{M}$ melatonin. Melatonin application had no effects on maize growth under normal condition, while it moderately alleviated the NaCl-induced inhibition of plant growth. The leaf area, biomass, and photosynthesis of melatonin-treated plants were higher than that of without melatonin under $\mathrm{NaCl}$ treatment. The osmotic potential was lower, and the osmolyte contents (including sucrose and fructose) were higher in melatonin-treated plants. Meanwhile, the decreases in $\mathrm{Na}^{+}$content and increases in $\mathrm{K}^{+} / \mathrm{Na}^{+}$ratio were found in shoots of melatonin-applied plant under salt stress. Moreover, both enzymatic and nonenzymatic antioxidant activities were significantly increased in leaves with melatonin application under salt treatment. These results clearly indicate that the exogenous melatonin-enhanced salt tolerance under short-term treatment could be ascribed to three aspects, including osmotic adjustment, ion balance, and alleviation of salt-induced oxidative stress.
\end{abstract}

Keywords: salt stress; osmotic potential; ion toxicity; antioxidant capacity

\section{Introduction}

Melatonin is a natural pleiotropic biomolecule which can be widely found in both plants and animals. Most previous studies have shown that melatonin is involved in regulating plant seed germination, rooting, flowering, photosynthesis, and leaf senescence [1-4]. In plants, melatonin acts as a well-known antioxidant, which is able to mitigate the effects of various abiotic stresses, including salt, drought, cold, heat, nitrogen deficiency, heavy metal and UV-B exposure, etc. [5-9]. 
The alleviation of salt stress by exogenous melatonin has been evidenced in several crops, including maize, rice, soybean, cucumber, watermelon, sunflower, tomato, and so on [10-15]. The mechanism of melatonin in increasing salt stress tolerance can be epitomized: increasing the activities of antioxidant enzymes, protecting photosynthetic system, as well as reducing $\mathrm{Na}^{+}$uptake by inhibiting bypass flow [2,12,15-18]. Also, transcriptomes have demonstrated that plant hormones, like abscisic acid (ABA), auxin, and gibberellin (GA), participated in the signaling pathways of melatonin-regulating salt stress responses [19]. Recently, Ke [20] reported that polyamine metabolism was involved in melatonin-induced moderation of salt stress by regulating the ion uptake and leaf senescence.

Salinity injured plants through two phases: osmotic stress and ionic toxicity. Osmotic stress induced by high concentrations of salts in culture solution limits the plant water absorption. The influence of osmotic stress on plants could occur after few hours of salt exposure, affects leaf water status, disturbs the photosynthetic system, reduces carbon assimilation, and inhibits the leaf elongation largely. With the prolongation of exposure time, the $\mathrm{Na}^{+}$concentration in old leaves would be over the threshold of toxicity, which accelerated the leaf senescence and further inhibited plant growth [21-23]. Correspondingly, plants improve salt tolerance through two ways: osmotic adjustment and mitigation of ion toxicity [23-25].

Previous studies have focused on the roles of melatonin in reducing shoot $\mathrm{Na}^{+}$content and in improving the antioxidant capacity $[2,16,17]$. In contrast, the osmotic adjustment by melatonin has not been paid enough attention. Osmotic stress not only has an immediate influence on growth but also has a more significant influence on growth rate in the early stage of salt stress than ionic toxicity [23]. Although exogenous melatonin application on osmotic stress regulation has been referred to in previous studies, most of the studies were focused on long-term salt stress, where the ion toxicity is more prominent $[2,26]$. Thus, the effects and mechanisms of melatonin on plant salt stress tolerance should include two phases: osmotic stress and ionic toxicity. In addition, oxidative stress induced by ion toxicity also should be paid attention.

Soil salinity limits plant growth and degrades crop productivity [26]. Therefore, improving crop salt tolerance is important for crop production. Maize (Zea mays L.) is sensitive to salt stress, especially during the seedling stage $[2,16]$. Thus, this research investigated the performance of melatonin on alleviating salt stress in maize seedlings under short-term salt stress. Dry weight, chlorophyll content, leaf area, photosynthesis, water potential, levels of osmotic adjustment substances, ion accumulation, and antioxidative enzymes were measured under short-term salt stress either with or without melatonin application.

\section{Materials and Methods}

\subsection{Plant Growth Conditions and Salt Treatment}

Cheng Yu 888, a salt-sensitive maize (Zea mays L.) cultivar, was used in the current experiment. Seeds were surface sterilized with sodium hypochlorite (1\%) for $10 \mathrm{~min}$ and germinated on wet filter paper under dark for 3 days at $25^{\circ} \mathrm{C}$. The uniform maize seedlings were placed in $1 / 4$ Hoagland solution (HS) for 10 days; after that, half of the seedlings were transplanted into $1 / 4$ HS with $1 \mu \mathrm{M}$ melatonin (Sigma-Aldrich, St. Louis, MO, USA) added (group 1) and half were transplanted into $1 / 4$ HS with no melatonin added (group 2). Then, 3 days later, each group was divided into two subgroups for subsequent salt treatment. During the salt treatment, the plants were also treated with $1 \mu \mathrm{M}$ melatonin. Thus, the four treatments were control (1/4 HS), melatonin treatment $(1 / 4 \mathrm{HS}$ with $1 \mu \mathrm{M}$ melatonin), salt stress treatment (1/4 HS with $100 \mathrm{mM} \mathrm{NaCl})$, and salt and melatonin treatment (1/4 HS combined with $100 \mathrm{mM} \mathrm{NaCl}$ and $1 \mu \mathrm{M}$ melatonin). Each treatment included three replications, and each replication has 12 plants. The culture media were changed every three days. After 4 and 8 days of salt treatment, the third well-expanded leaves were measured and sampled between 9:00 a.m. and 11:00 a.m. The experiment was conducted in a growth chamber maintained at $28^{\circ} \mathrm{C}$ and $23^{\circ} \mathrm{C}$ for day and night temperatures, $12 \mathrm{~h}$ light and $12 \mathrm{~h}$ dark photoperiod, $450 \mu \mathrm{Mol} \mathrm{m}^{-2} \mathrm{~s}^{-1}$ 
photosynthetic photon flux density (PPFD), $45-55 \%$ relative humidity, and $400 \mathrm{ppm} \mathrm{CO}_{2}$ concentration. All experiments were repeated twice.

\subsection{Biomass and Leaf Area}

Shoots and roots of six plants were harvested from each treatment at various time points (4 and 8 days after salt treatment) and dried in an oven at $70{ }^{\circ} \mathrm{C}$ for $72 \mathrm{~h}$ to determine the shoot and root dry weight. The leaf area (LA) was estimated as described by Wang et al. [27]. Six biological repeats were included in each treatment.

\subsection{Chlorophyll, Gas Exchange Parameters, and Instantaneous Water Use Efficiency (WUEi)}

Chlorophyll concentration was determined by measuring the soil and plant analyzer development (SPAD) value (SPAD-502, Konica-Minolta, Tokyo, Japan). The top fully expanded leaf was selected, 8 points of each leaf were measured, and the average value was calculated. Photosynthetic rate, stomatal conductance, and transpiration rate of the top fully expanded leaf were determined between 9:00 a.m. and 11:00 a.m. by a portable photosynthesis system (LI-6400XT; LI-COR Biosciences, Lincoln, NE, USA). Environmental conditions of the leaf chamber were as follows: $1000 \mu \mathrm{Mol} \mathrm{m}{ }^{-2} \mathrm{~s}^{-1}$ photosynthetically active radiation, $50 \%$ humidity, $25^{\circ} \mathrm{C}$ leaf temperature, and $500 \mu \mathrm{Mol} \mathrm{s}^{-1}$ airflow. Instantaneous water use efficiency (WUEi) of the leaf was calculated by the ratio of photosynthetic rate/transpiration rate. Six replicates were included in each treatment.

\subsection{Leaf Relative Water Content, Water Potential, Osmotic Potential, and Turgor Pressure}

The third fully expanded leaf was harvested, and the fresh weight (FW) was weighed immediately. Turgid weight (TW) was measured by immersing leaf segments in distilled water for $6 \mathrm{~h}$; then, the dry weight (DW) was determined after leaf segments were dried in an oven at $70{ }^{\circ} \mathrm{C}$ for $24 \mathrm{~h}$. The relative water content (RWC) was calculated using the following equation according to Chen et al. [2]:

$$
R W C=\frac{F W-D W}{T W-D W} \times 100
$$

Leaf osmotic potential $(\Psi \pi)$ and water potential $(\Psi w)$ were determined according to Chen et al. [24] by using a dew point microvolt meter (Model 5520, Wescor, Logan, UT, USA) and a pressure chamber (Model 1000, PMS instrument Co., Corvallis, OR, USA), respectively. Before determining the leaf osmotic potential, samples were put into $0.5-\mathrm{mL}$ tubes and frozen in liquid nitrogen for 30 minutes. After thawing, the 0.5-mL tubes were drilled at the bottom, placed into 1.5-mL tubes and centrifuged to gather the cell sap ( $4000 \mathrm{rpm}$ for $5 \mathrm{~min}$ ). The osmolarity was determined, and the osmotic potential was calculated. The turgor pressure ( $\Psi p)$ was calculated as the difference between $\Psi w$ and $\Psi \pi$. Three biological repeats were included in each treatment.

\subsection{Sucrose, Fructose, and Proline Levels}

The sucrose and fructose contents were determined by HPLC (Shimadzu, Kyoto, Japan) as described previously [25]. Frozen leaf tissues $(0.1 \mathrm{~g})$ were ground and extracted in $2 \mathrm{~mL}$ of $85 \%(v / v)$ ethanol. Extracts were heated in a water bath at $80^{\circ} \mathrm{C}$ for $1 \mathrm{~h}$, and the ethanol phase was dried. Samples were dissolved in $1 \mathrm{~mL}$ of water and passed through a $0.45-\mu \mathrm{m}$ membrane filter. The samples were separated by using the Shim-pack ISA-07/S2504 column under the following program: 0-50 $\mathrm{min}, 100 \%$ buffer A-100\% buffer B; 50-65 $\mathrm{min}, 100 \%$ buffer B; and $65-90 \mathrm{~min}, 100 \%$ buffer A at a flow rate of $0.6 \mathrm{~mL} \mathrm{~min}^{-1}$. Buffer A consists of $0.1 \mathrm{M}$ potassium borate; buffer $\mathrm{B}$ consists of $0.4 \mathrm{M}$ potassium borate. The L-arginine reagent ( $3 \%$ borate was contained in $1 \% \mathrm{~L}$-arginine) was delivered at a flow rate of $0.5 \mathrm{~mL} \mathrm{~min}^{-1}$, and the reaction oven was set at $150{ }^{\circ} \mathrm{C}$. Sugars were determined at excitation of $320 \mathrm{~nm}$ and emission of $430 \mathrm{~nm}$ by using a fluorescence detector. Sugar standards (Sigma-Aldrich, St. Louis, MO, USA) were used to obtain the standard curves. 
To determine proline contents, frozen leaf tissues $(0.1 \mathrm{~g})$ were ground and extracted with $3 \%$ sulfosalicylic acid. Proline levels were measured according to Bates et al. [28], with slight modifications. Briefly, the reaction was activated by the addition of $1 \mathrm{~mL}$ ninhydrin and glacial acetic acid reagent. Samples were boiled for $1 \mathrm{~h}$ at $95^{\circ} \mathrm{C}$. The reaction was stopped by putting the samples on ice, and the absorbance was determined using a spectrophotometer (UV-2550; Shimadzu, Kyoto, Japan) at $520 \mathrm{~nm}$. Each treatment had three biological replicates.

\section{6. $\mathrm{Na}^{+}$and $\mathrm{K}^{+}$Contents}

The levels of $\mathrm{Na}^{+}$and $\mathrm{K}^{+}$in $0.5 \mathrm{~g}$ of dried shoot or root samples were determined according to Storey [29]. Briefly, the dried samples were ground and digested in nitric acid on a hot stove at $200{ }^{\circ} \mathrm{C}$. The $10 \%$ nitric acid $(v / v)$ was used to resolve the residue. The absorbance was measured by a flame emission spectrophotometer (FP 640, Shanghai Xinyi Instrument Co., Ltd., China). Each treatment had three biological replicates.

\subsection{Hydrogen Peroxide and Malondialdehyde}

To determine the hydrogen peroxide $\left(\mathrm{H}_{2} \mathrm{O}_{2}\right)$ content, frozen leaf tissues $(0.2 \mathrm{~g})$ were ground in $2 \mathrm{~mL} 0.1 \%(w / v)$ trichloroacetic acid (TCA). Extracts were mixed with a buffer containing $1 \mathrm{M}$ potassium iodide (KI) and $10 \mathrm{mM}$ potassium phosphate. $\mathrm{H}_{2} \mathrm{O}_{2}$ was measured according Loreto and Velikova [30]. Malondialdehyde (MDA) contents in leaf of maize plants were determined, as described previously [31]. The absorbance was achieved at $520 \mathrm{~nm}$ by using a spectrophotometer (UV-2550; Shimadzu, Kyoto, Japan). Three biological repeats were included in each treatment.

\subsection{Activities of Enzymatic and Nonenzymatic Antioxidant}

Plant tissues $(0.2 \mathrm{~g})$ were mixed with a buffer containing $2 \mathrm{mM}$ ascorbate, $2.5 \mathrm{mM}$ $\mathrm{N}$-2-hydroxyethylpiperazine-N-ethane-sulphonicacid (HEPES), $0.2 \mathrm{mM}$ ethylenediaminetetraacetic acid (EDTA), and 2\% polyvinylpyrrolidone. Extracts were centrifuged at 12,000 $\times \mathrm{g}$ for $30 \mathrm{~min}$ at $4{ }^{\circ} \mathrm{C}$. The supernatant was used to determine the activities of enzymatic antioxidant. Also, the buffer with no ascorbate added was used for determining the activity of superoxide dismutase (SOD). Activities of SOD, catalase (CAT), and peroxidase (POD) were measured according to Beauchamp and Fridovich [32], Hamurcu et al. [33], and Kochba et al. [34], respectively. The free-radical scavenging activity (nonenzymatic antioxidant ability) was assessed by DPPH (1,1-Diphenyl-2-picryl-hydrazyl) according to Wang et al. [35]. Three biological repeats were included in each treatment.

\subsection{The Contents of Endogenous Melatonin}

Endogenous melatonin contents in leaf and root samples were determined according to Byeon and Back [36] by HPLC (Shimadzu, Kyoto, Japan). Freeze dried tissues ( $0.5 \mathrm{~g}$ ) were ground and extracted with $5 \mathrm{ml}$ chloroform. The homogeneous mixtures were centrifuged at $10,000 \times g$ for $15 \mathrm{~min}$ at $4{ }^{\circ} \mathrm{C}$, and then, the chloroform phase was evaporated. Samples were dissolved in $1 \mathrm{ml}$ methanol and passed through a $0.45-\mu \mathrm{m}$ membrane filter. The samples were separated on the Shim-pack VP-ODS column under the following program: $0-27 \mathrm{~min}, 42-50 \%$ methanol; $27-45 \mathrm{~min}$, and 50\% methanol at a flow rate of $0.15 \mathrm{~mL} \mathrm{~min}^{-1}$. Melatonin was determined at excitation of $280 \mathrm{~nm}$ and emission of $348 \mathrm{~nm}$ by using a fluorescence detector. Melatonin standard (Sigma-Aldrich, St. Louis, MO, USA) was used to obtain the standard curve. Three biological repeats were included in each treatment.

\subsection{Statistical Analysis}

All data are shown as means \pm SE (standard error). Statistical analysis was carried out using SPSS Statistics software (Version 21.0, SPSS, Chicago, IL, USA). Significant differences between the means were determined using Duncan test at $p<0.05$. 


\section{Results}

\subsection{Effect of Salt and Melatonin Treatments on Plant Growth}

Under normal growth conditions, exogenous melatonin application had no effect on promoting plant growth (Figure 1). Salt stress significantly reduced the total dry weight by $37.3 \%$ and $46.3 \%$ after 4 and 8 days of treatment. In contrast, the dry weight of salt combined with melatonin treatment just reduced the dry weight by $19.7 \%$ and $29.4 \%$ after 4 and 8 days of treatment, respectively (Figure 1C). Similarly, leaf area was not affected by supplementary melatonin without salt stress. $\mathrm{NaCl}$ alone reduced plant leaf area by $36.2 \%$ and $43.8 \%$ after 4 and 8 days compared with control, but the reduction was only $20.0 \%$ and $30.5 \%$ in the treatment of salt combined with melatonin (Figure $1 \mathrm{D})$. The results showed that melatonin alleviated the salt-induced growth inhibition.
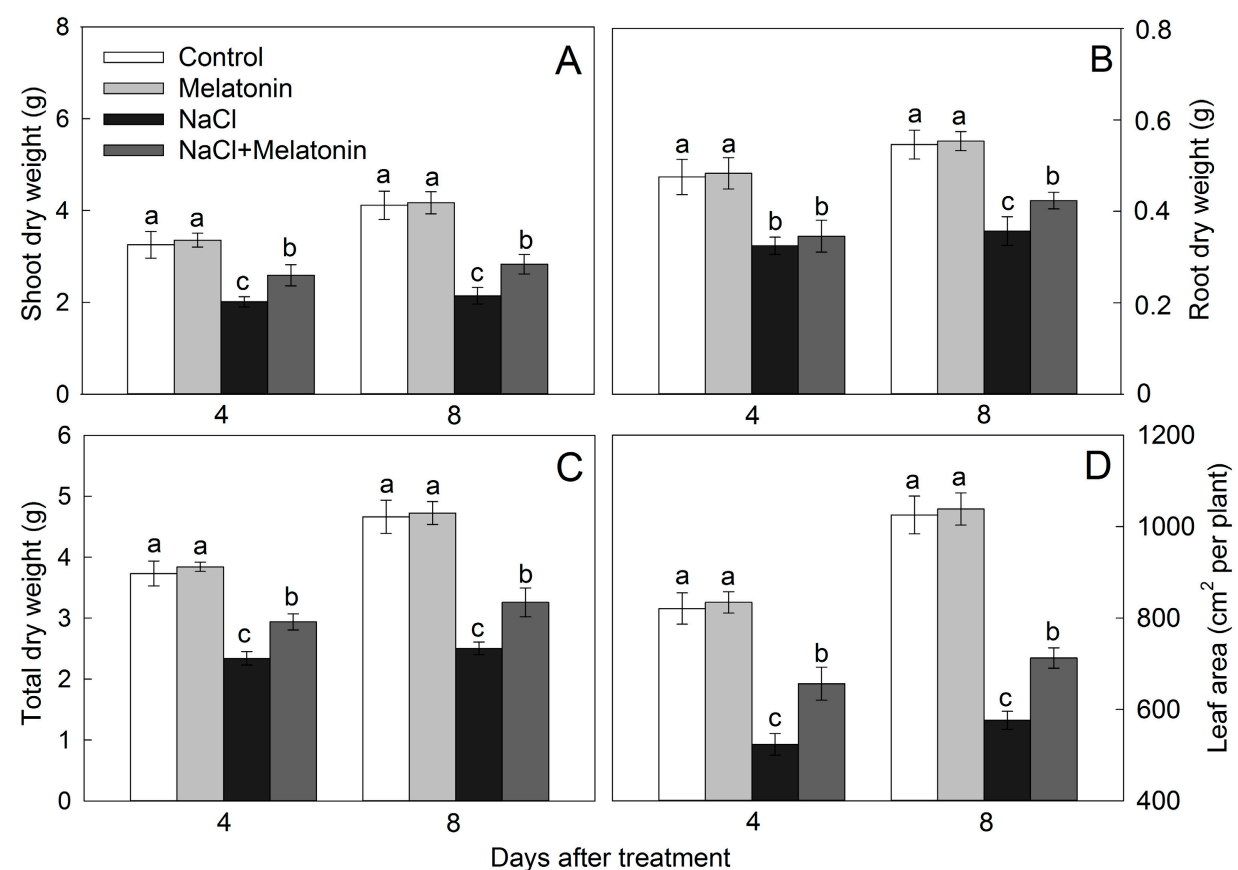

Figure 1. Effects of melatonin and salt on shoot dry weight (A), root dry weight (B), total dry weight (C), and leaf area (D) of maize: All parameters were measured after 4 and 8 days of treatment. Values are presented as the mean \pm SE $(n=6)$. Different letters indicate significant differences at $p<0.05$.

\subsection{Effect of Salt and Melatonin Treatments on Photosynthetic Rate and Chlorophyll Content}

In the absence of salt stress, photosynthetic rate, stomatal conductance, or transpiration rate were not affected by melatonin application (Figure $2 \mathrm{~A}-\mathrm{C}$ ). $\mathrm{NaCl}$ alone significantly reduced those photosynthetic parameters, and this descending trend was moderated by melatonin application. After 8 days of $\mathrm{NaCl}$ stress, photosynthetic rate, stomata conductance, and transpiration rate with melatonin added were $23.7 \%, 40.2 \%$, and $50.6 \%$ higher than that of the non-melatonin treatment, respectively (Figure 2A-C). Melatonin did not affect leaf chlorophyll content (SPAD values) under both normal and salt conditions during the experimental period (Figure 2D). WUEi was enhanced after salt treatment, but it decreased by melatonin (Figure 2E). 


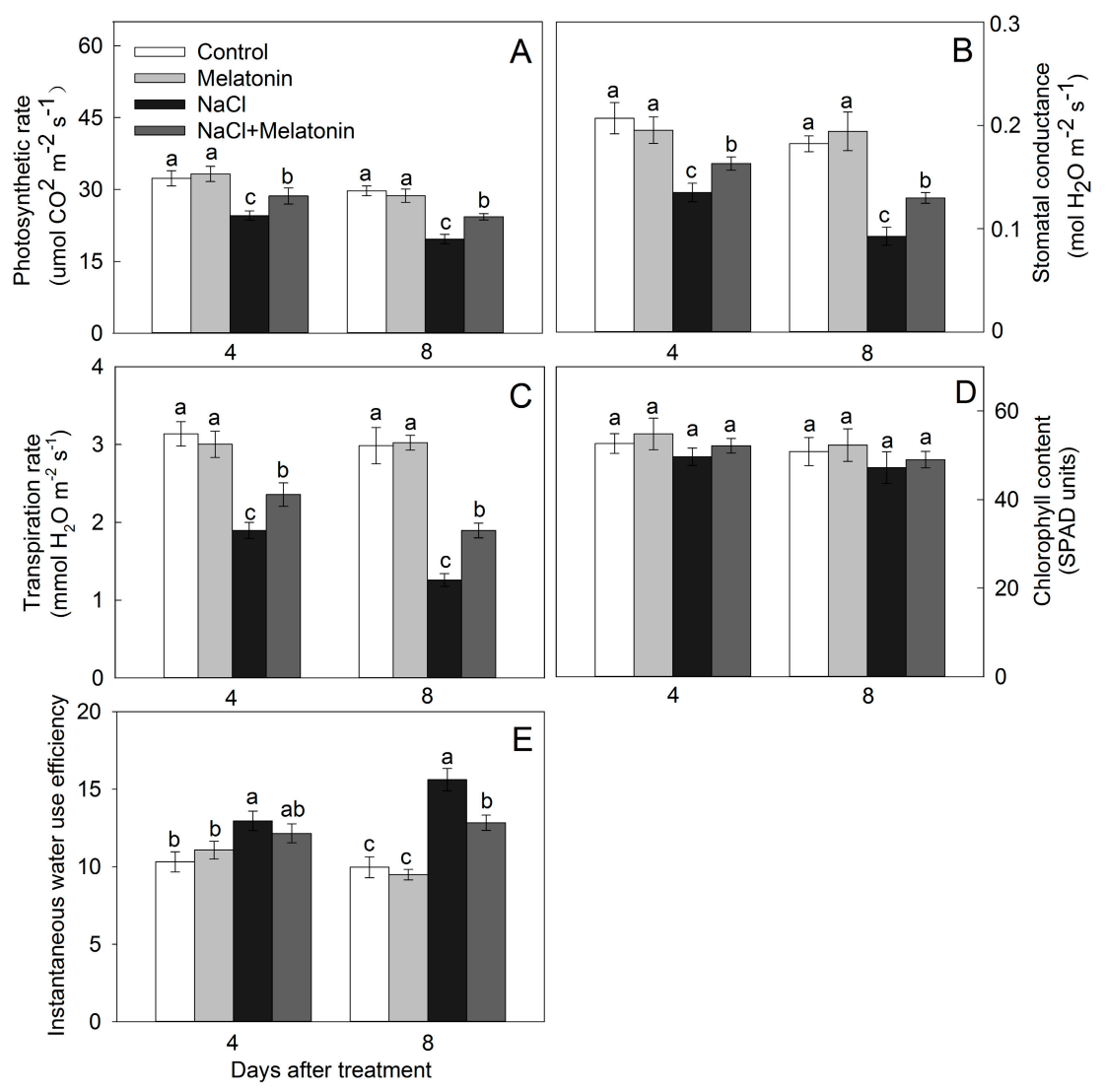

Figure 2. Effects of melatonin and salt on photosynthetic rate (A), stomatal conductance (B), transpiration rate (C), chlorophyll content (SPAD units) (D), and instantaneous water use efficiency (WUEi) (E) of maize leaves: All parameters were measured after 4 and 8 days of treatment. Values are presented as the mean \pm SE $(n=6)$. Different letters indicate significant differences at $p<0.05$.

\subsection{Effect of Salt and Melatonin Treatments on Leaf Water Status}

The RWC, $\Psi \mathrm{w}, \Psi \pi$, and $\Psi \mathrm{p}$ were maintained stable and were not influenced by the exogenous melatonin without salt stress (Figure 3). Salt stress significantly reduced the RWC by $16.6 \%$ and $25.3 \%$ after 4 and 8 days of treatment. However, when plants were treated with $\mathrm{NaCl}$ combined with melatonin, RWC was decreased by only $8.2 \%$ and $15.6 \%$ after being treated for 4 and 8 days, respectively (Figure 3A). Salt stress significantly decreased the $\Psi w$, and it became more extensive with the prolongation of salt treatment time. The $\Psi \mathrm{w}$ was not affected by melatonin application under $\mathrm{NaCl}$ stress condition (Figure 3B). The $\Psi \pi$ was decreased by $\mathrm{NaCl}$, and it was further decreased by melatonin. Compared with control, $\Psi \pi$ in the plants under treatment of salt combined with melatonin decreased by $66.7 \%$ and $81.6 \%$ after treatment for 4 and 8 days; in contrast, $\mathrm{NaCl}$ alone just reduced $\Psi \pi$ by $41.7 \%$ and $57.9 \%$, respectively (Figure $3 \mathrm{C}$ ). The $\Psi \mathrm{p}$ was significantly increased by salt stress, and it was further increased by melatonin application (Figure 3D).

\subsection{Effect of Salt and Melatonin Treatments on Soluble Sugar and Proline Contents}

Melatonin had no effect on sucrose, fructose, and proline contents under normal growth condition (Figure 4). Water soluble sugar (sucrose and fructose) contents were enhanced after salt treatment, and they were further enhanced by melatonin under salt treatment (Figure $4 \mathrm{~A}, \mathrm{~B})$. Salt stress increased the proline contents largely, but it was decreased by melatonin application. In addition, the salt-induced increase of proline accumulation was completely eliminated by the melatonin application after 8 days of salt treatment (Figure 4C). 


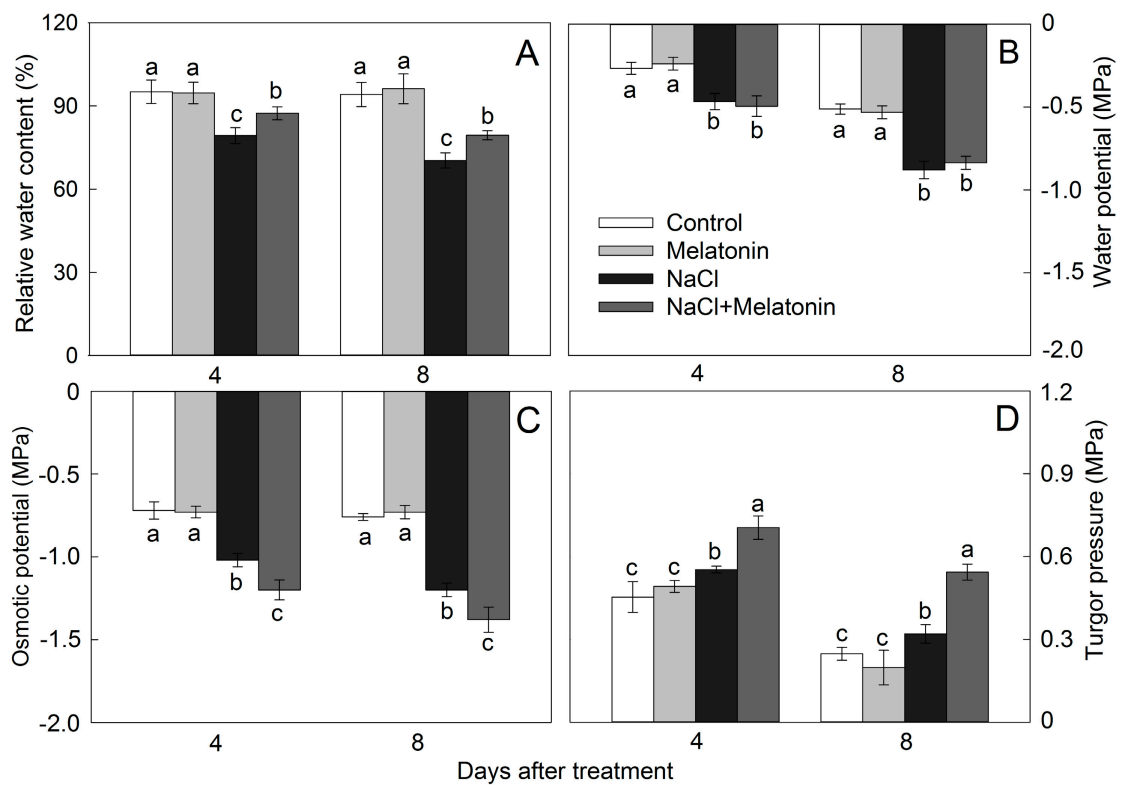

Figure 3. Effects of melatonin and salt stress on relative water content (A), water potential (B), osmotic potential (C), and turgor pressure (D) of maize leaves: All parameters were measured after 4 and 8 days of treatment. Values are presented as the mean \pm SE $(n=6)$. Different letters indicate significant differences at $p<0.05$.
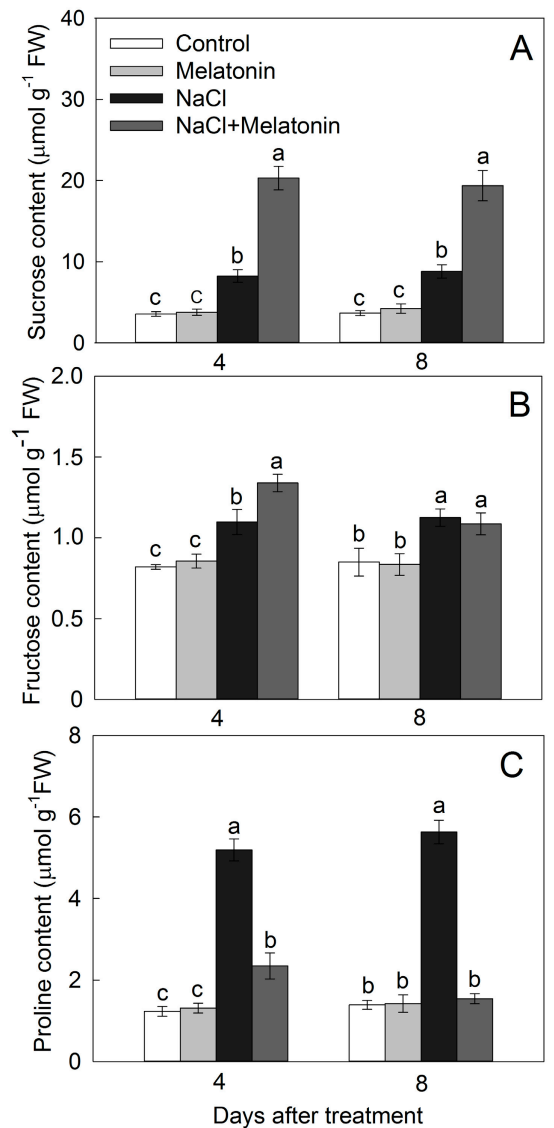

Figure 4. Effects of melatonin and salt stress on sucrose content (A), fructose content (B), and proline content $(\mathbf{C})$ of maize leaves: All parameters were measured after 4 and 8 days of treatment. Data were shown as mean \pm SE $(n=3)$. Different letters indicate significant differences at $p<0.05$. 


\subsection{Effect of Salt and Melatonin Treatments on $\mathrm{Na}^{+}$and $\mathrm{K}^{+}$Accumulation}

Compared with control, the $\mathrm{Na}^{+}$contents were enhanced while the $\mathrm{K}^{+}$contents were reduced both in shoots and roots by salt stress, leading to a remarkable decrease of the $\mathrm{K}^{+} / \mathrm{Na}^{+}$ratio (Figure 5). Melatonin application had no significant effect on $\mathrm{K}^{+}$content under nonsaline condition, while it enhanced $\mathrm{K}^{+}$content under salt stress both in roots and shoots (Figure 5C,D). Melatonin reduced the $\mathrm{Na}^{+}$content in shoots but not in roots (Figure $5 \mathrm{~A}, \mathrm{~B}$ ). Under salt stress, the $\mathrm{K}^{+} / \mathrm{Na}^{+}$was not enhanced by melatonin application except for that in shoot after 8 days of treatment (Figure 5F).
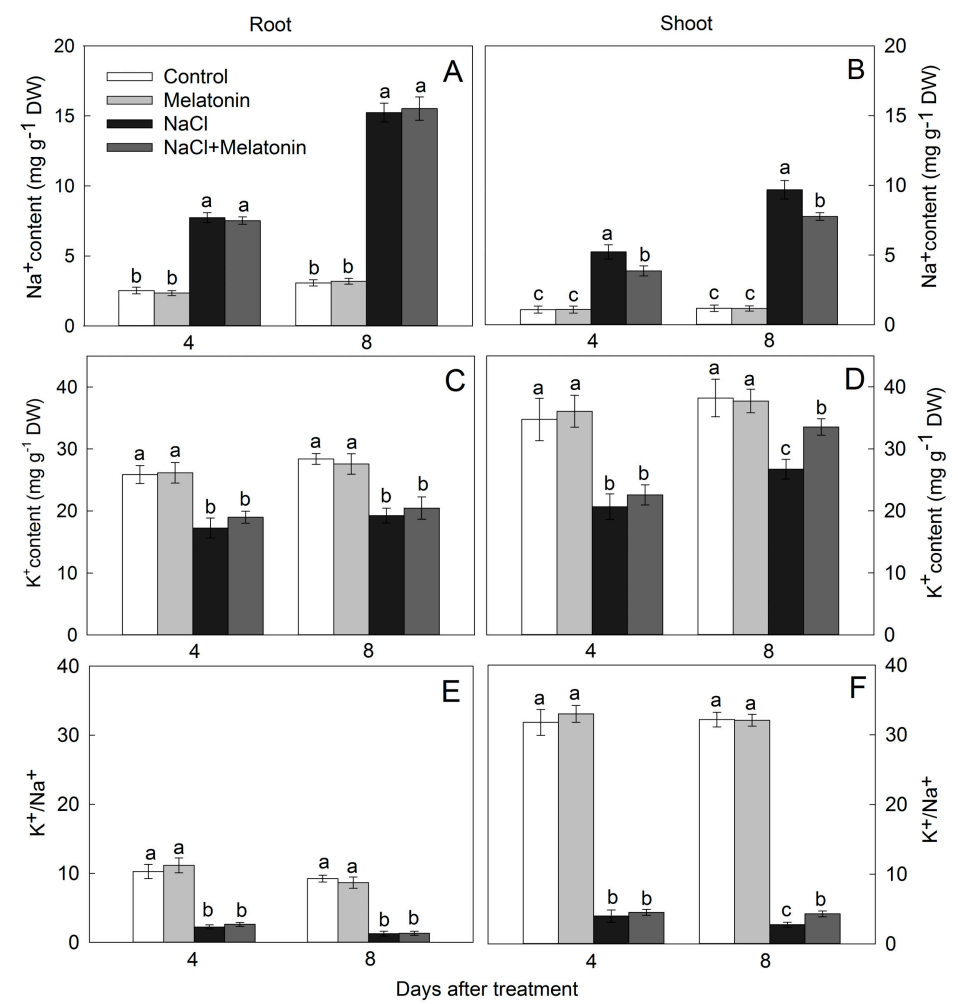

Figure 5. Effects of melatonin and salt stress on $\mathrm{Na}^{+}$content $(\mathbf{A}, \mathbf{B}), \mathrm{K}^{+}$content $(\mathbf{C}, \mathbf{D})$, and $\mathrm{K}^{+} / \mathrm{Na}^{+}$ratio $(\mathbf{E}, \mathbf{F})$ of maize roots and shoots: All parameters were measured after 4 and 8 days of treatment. Values are presented as the mean \pm SE $(n=3)$. Different letters indicate significant differences at $p<0.05$.

\subsection{Effect of Salt and Melatonin Treatments on Leaf Hydrogen Peroxide $\left(\mathrm{H}_{2} \mathrm{O}_{2}\right)$ and Malondialdehyde} $(M D A)$ Contents

With no salt treatment, the levels of $\mathrm{H}_{2} \mathrm{O}_{2}$ and MDA were not affected by melatonin. Under salt treatment, $\mathrm{H}_{2} \mathrm{O}_{2}$ and MDA were largely accumulated in leaves, but this accumulation was partly moderated by application of melatonin (Figure 6). Compared with control, leaf $\mathrm{H}_{2} \mathrm{O}_{2}$ contents in plants under the treatment of salt combined with melatonin were increased by $82.3 \%$ and $134.5 \%$ after treated for 4 and 8 days; in contrast, $\mathrm{NaCl}$ alone increased $\mathrm{H}_{2} \mathrm{O}_{2}$ by $141.7 \%$ and $197.0 \%$, respectively (Figure 6A). Similarly, $\mathrm{NaCl}$ alone enhanced leaf MDA content by $174.8 \%$ and $310.9 \%$ after 4 and 8 days as compared with control, but the enhancements were only $108.3 \%$ and $217.9 \%$ in the treatment of salt combined with melatonin (Figure 6B). 


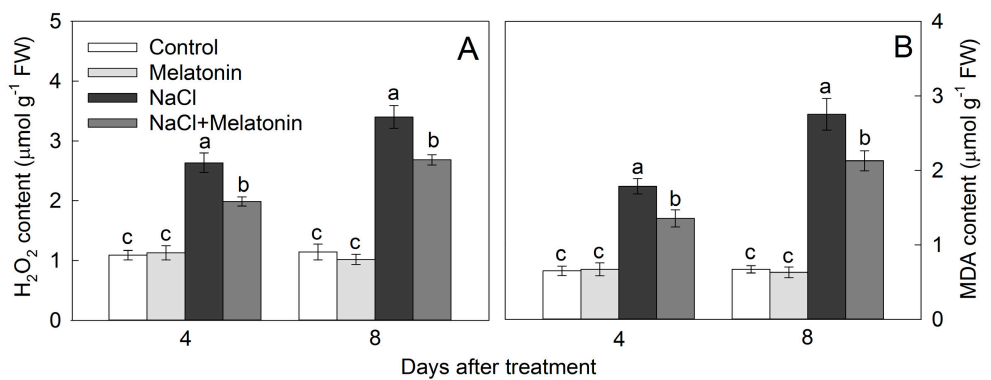

Figure 6. Effects of melatonin and salt stress on hydrogen peroxide content (A) and malondialdehyde content (B) of maize leaves: All parameters were measured after 4 and 8 days of treatment. Values are presented as the mean \pm SE $(n=3)$. Different letters indicate significant differences at $p<0.05$.

\subsection{Effect of Salt and Melatonin Treatments on Enzymatic and Nonenzymatic Antioxidant Ability}

As shown in Figure 7, the activities of superoxide dismutase (SOD), catalase (CAT), peroxidase (POD), and DPPH-radical scavenging ability were maintained stable and were not influenced by the exogenous melatonin without salt stress. Under salt stress, antioxidant enzyme activities (SOD, CAT, and POD) were stimulated, and melatonin application further enlarged this profitable trend. For example, after 8 days of salt treatment, the SOD, CAT, and POD activities were increased by $115.2 \%$, $112.1 \%$, and $56.5 \%$, respectively, compared to control (Figure $8 \mathrm{~A}-\mathrm{C}$ ), while with melatonin application, the SOD, CAT, and POD activities were further 59.5\%, 23.7\%, and $22.2 \%$ higher than that of under only salt treatment, respectively (Figure $7 \mathrm{~A}-\mathrm{C}$ ). $\mathrm{NaCl}$ treatment alone significantly reduced the DPPH activity by $15.6 \%$ and $21.5 \%$ after 4 and 8 days. However, when plants were treated by salt combined with melatonin, DPPH activities were reduced by only $6.2 \%$ and $10.7 \%$ after treatment for 4 and 8 days, respectively (Figure 7D).

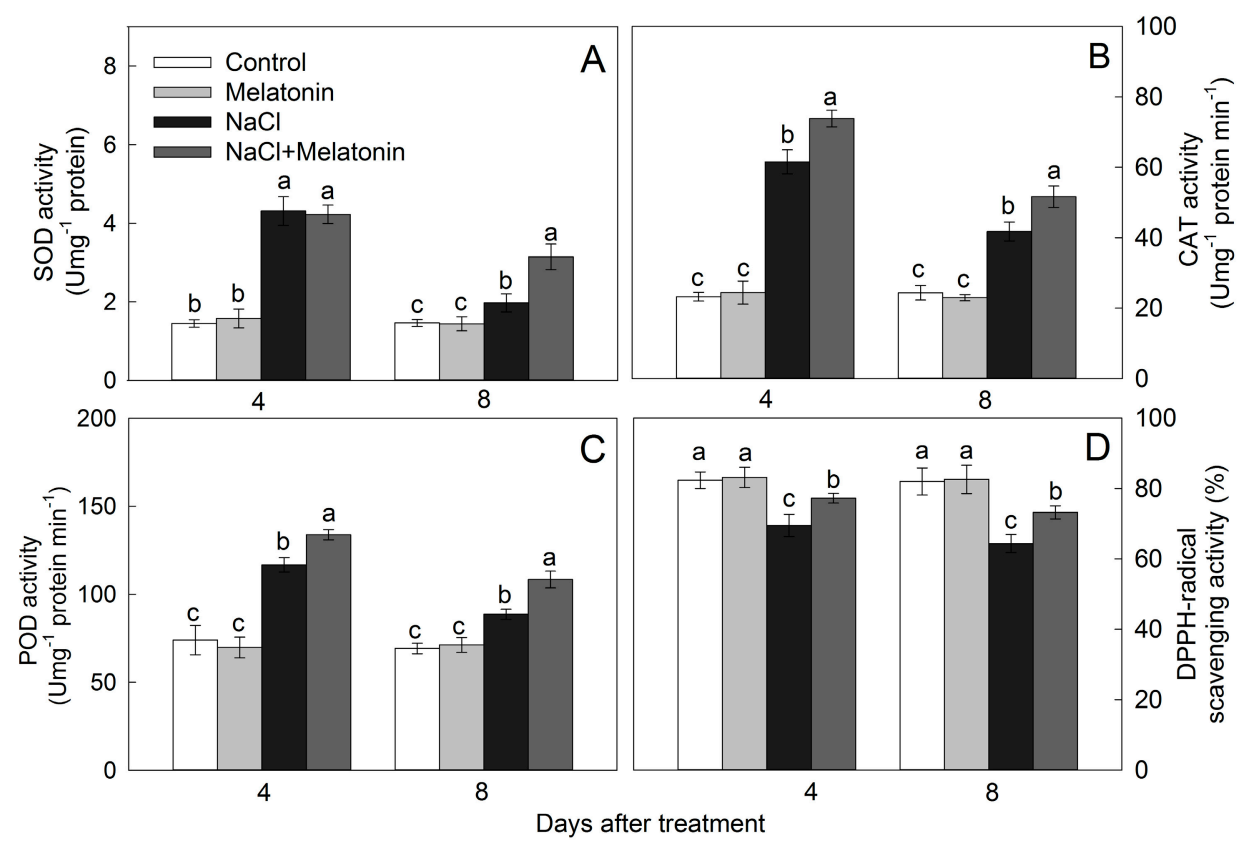

Figure 7. Effects of melatonin and salt stress on the activities of superoxide dismutase (A), catalase (B), peroxidase (C) and 1,1-Diphenyl-2-picryl-hydrazyl (D) of maize leaves: All parameters were measured after 4 and 8 days of treatment. Values are presented as the mean $\pm \mathrm{SE}(n=3)$. Different letters indicate significant differences at $p<0.05$. 


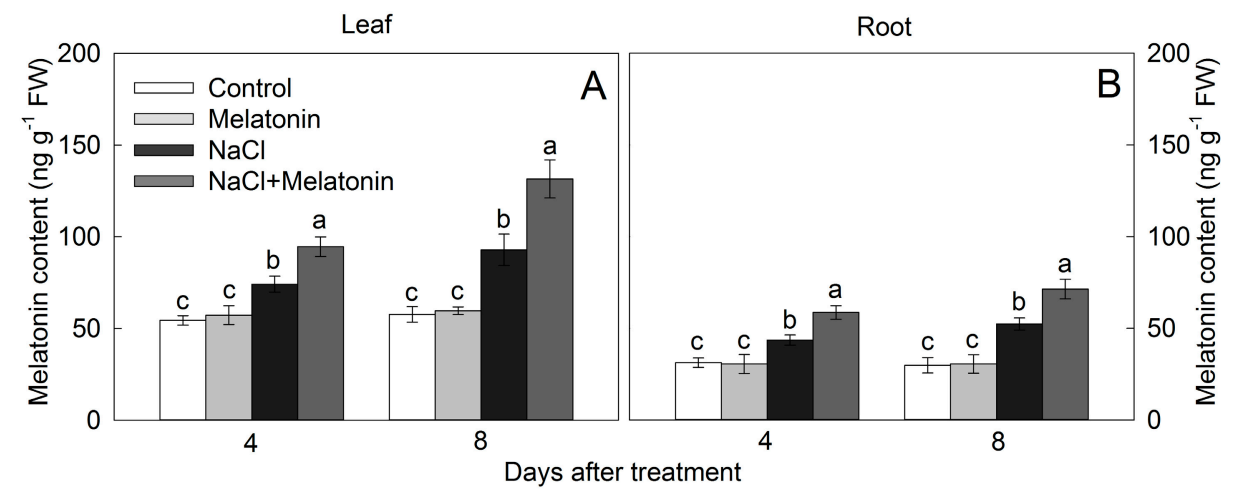

Figure 8. Effects of melatonin and salt stress on endogenous melatonin content of maize leaves (A) and roots (B): All parameters were measured after 4 and 8 days of treatment. Values are presented as the mean \pm SE $(n=3)$. Different letters indicate significant differences at $p<0.05$.

\subsection{Effect of Salt and Melatonin Treatment on Endogenous Melatonin Contents}

The endogenous melatonin contents in both leaf and root were not influenced by the exogenous melatonin without salt stress (Figure 8). Salt treatment significantly increased the endogenous melatonin contents, and it was further increased with prolonged salt treatment period. The endogenous melatonin contents were largely increased by exogenous melatonin application under salt stress condition both in leaves and roots. The endogenous melatonin levels in melatonin-treated plants were improved by $41.7 \%$ in leaves and by $60.8 \%$ in roots compared with those no-melatonin-treated plants after 8 days of salt stress treatment (Figure $8 \mathrm{~A}, \mathrm{~B}$ ).

\section{Discussion}

Previous reports indicated that exogenous melatonin may play a positive role on the growth of diverse plant species under salt stress condition [11,13-15]. Our results displayed that the growth inhibition caused by $\mathrm{NaCl}$ stress was mitigated by melatonin application, indicating that melatonin could improve the salt tolerance in maize. Maintaining the higher biomass in melatonin-applied plants could be ascribed to the holding of a high photosynthetic capacity in those plants $[2,15,37]$. In the current study, melatonin application mitigated the salt-induced photosynthetic inhibition, which is in accordance with the observations of previous researches (Figure 2).

Osmotic adjustment is an effective strategy for plants to resist salt-induced osmotic stress $[25,38]$. In this study, the plants with melatonin application had higher RWC than that without melatonin (Figure 3A), suggesting that melatonin alleviated the salt-induced osmotic stress, at least partially. Meanwhile, melatonin-treated plants had higher $\Psi \mathrm{p}$, which could drive stomata open and contribute to maintaining a higher photosynthetic rate. Furthermore, melatonin-treated plants had a huge reduction in $\Psi \pi$ than that of untreated ones under salt stress (Figure 3C). The lower $\Psi \pi$ means the higher osmotic adjustment capacity [24]. The effect of melatonin on the positive water statuses has been reported in a previous study, such as under drought and salt conditions $[2,39,40]$. Those results indicate that melatonin application could alleviate the plant water status by improving the osmotic adjustment, which is a general way in response to osmotic stress induced by both salt and drought stresses.

Plants improve the osmotic adjustment capacity by synthesis and accumulation of organic osmolytes under salt stress [41,42]. Soluble sugar is considered as one of the key osmolytes for osmotic adjustment. In our study, levels of sucrose and fructose were remarkably enhanced in melatonin-treated plants under $\mathrm{NaCl}$ treatment (Figure 4A,B). A relevant research also indicated that melatonin increased the level of soluble sugar in Arabidopsis under osmotic stress induced by salt and drought [43]. Another vital osmolyte is proline, and its effect on osmotic adjustment has been extensively demonstrated [44,45]. However, other researches contended that accumulation of proline was an indicator of stress injury rather than a label of stress tolerance [46,47]. In addition, an opinion that decreased production of 
proline could benefit the plant by saving more energy for coping with stresses because the proline synthesis demanding huge energy was favored by some researchers $[48,49]$. In our research, salt stress remarkably increased proline content in leaves, but this enhancement was markedly eliminated by melatonin application (Figure 4C). Our findings are more likely to approve the opinion that accumulation of proline is an indicator of injury rather than a tolerant performance. Together, sucrose and fructose were enhanced under salt stress condition and they were further increased under salt combined with melatonin treatment, suggesting that sucrose and fructose were contributing to osmotic adjustment in this study.

Leaves are an important metabolic organ; maintaining a low $\mathrm{Na}^{+}$contents and a high cytosolic $\mathrm{K}^{+} / \mathrm{Na}^{+}$ratio in leaves is vital for maintaining cellular metabolisms [50,51]. Excessive $\mathrm{Na}^{+}$accumulation resulted in water and mineral nutrient deficiency as well as ion imbalance in the cytosol [23]. Previous researches suggested that melatonin could reduce the $\mathrm{Na}^{+}$content in the shoot of rice [17], maize [16], and Malus hupehensis [52]. In this study, $\mathrm{Na}^{+}$contents in shoot were lower in melatonin-treated plants than that without melatonin under salt stress condition (Figure 5B), indicating that the loading of xylem $\mathrm{Na}^{+}$in roots was repressed by melatonin. Meanwhile, melatonin improved the $\mathrm{K}^{+}$absorption under salt stress, confirmed in this study (Figure 5D). Previous researches revealed that the transcriptional level of OsSOS1 was upregulated by melatonin application in the root of rice [17]. The increases of SOS1 expression in NaCl-treated roots by melatonin application may directly contribute to $\mathrm{Na}^{+}$export from roots and retention in stems, thus preventing $\mathrm{Na}^{+}$from reaching photosynthetic leaf tissues. Zhao et al. [53] suggested that melatonin could maintain ion balance through the SOS-mediated $\mathrm{Na}^{+}$efflux pathway and that $\mathrm{NO}$ operates downstream of melatonin, improving salinity tolerance. Melatonin-promoted $\mathrm{K}^{+}$uptake through upregulation of $\mathrm{K}^{+}$transporter genes (AKT1 and HKT1) in Malus plants [54] has also been proved.

Salt stress destroys the balance between reactive oxygen species (ROS) production and removal and induces lipid peroxidation [55]. Melatonin is a well-documented antioxidant and plays a vital role in mitigating abiotic stress-induced oxidative stress by scavenging ROS either directly or indirectly in plants $[4,14,56]$. Previous studies displayed that melatonin application leads to maintaining the low contents of $\mathrm{H}_{2} \mathrm{O}_{2}$ and MDA by enhancing the antioxidative capacity in response to various stresses [16,52,57]. Similarly, in the present study, the decreased $\mathrm{H}_{2} \mathrm{O}_{2}$ and MDA contents were found in melatonin-treated plants along with the increased SOD, CAT, POD, and DPPH-radical scavenging activities under stress condition, which confirmed the remarkable role of melatonin in improving salt stress tolerance through enhancing the plant antioxidative ability (Figures 6 and 7). Previous studies showed that exogenous melatonin could be directly uptake by roots $[7,16]$. In this study, salt stress induced accumulation of melatonin in vivo and it was largely increased by exogenous melatonin application. Thus, the results confirmed the previous studies that melatonin played an important role in alleviating the stress tolerance $[2,58,59]$. However, the levels of melatonin in vivo were not increased by exogenous melatonin application under normal growth condition. The exogenous melatonin application tended to increase the endogenous melatonin in most studies, but the increasing extents were less under normal growth condition than under salt stress [2,20]. In some studies, the effect of the exogenous melatonin on endogenous melatonin contents becomes unobvious with prolonged treatment time [19]. It is suggested that melatonin in plants may be maintained at a stable content under normal growth condition, but it will be increased greatly when they are needed for stress responses.

In general, the growth of maize seedlings was severely inhibited by salt stress treatment. In the present research, the alleviation of short-term salt stress by exogenous melatonin application in maize seedlings was investigated and the potential mechanisms are presented as shown in Figure 9. Exogenous application of melatonin-enhanced salt tolerance could be ascribed to three aspects: osmotic adjustment, ion balance, and alleviation of salt-induced oxidative stress. The results of this study suggest that melatonin has great potential in improving salt tolerance in crops, and field studies are needed to further confirm its performance in the future. 


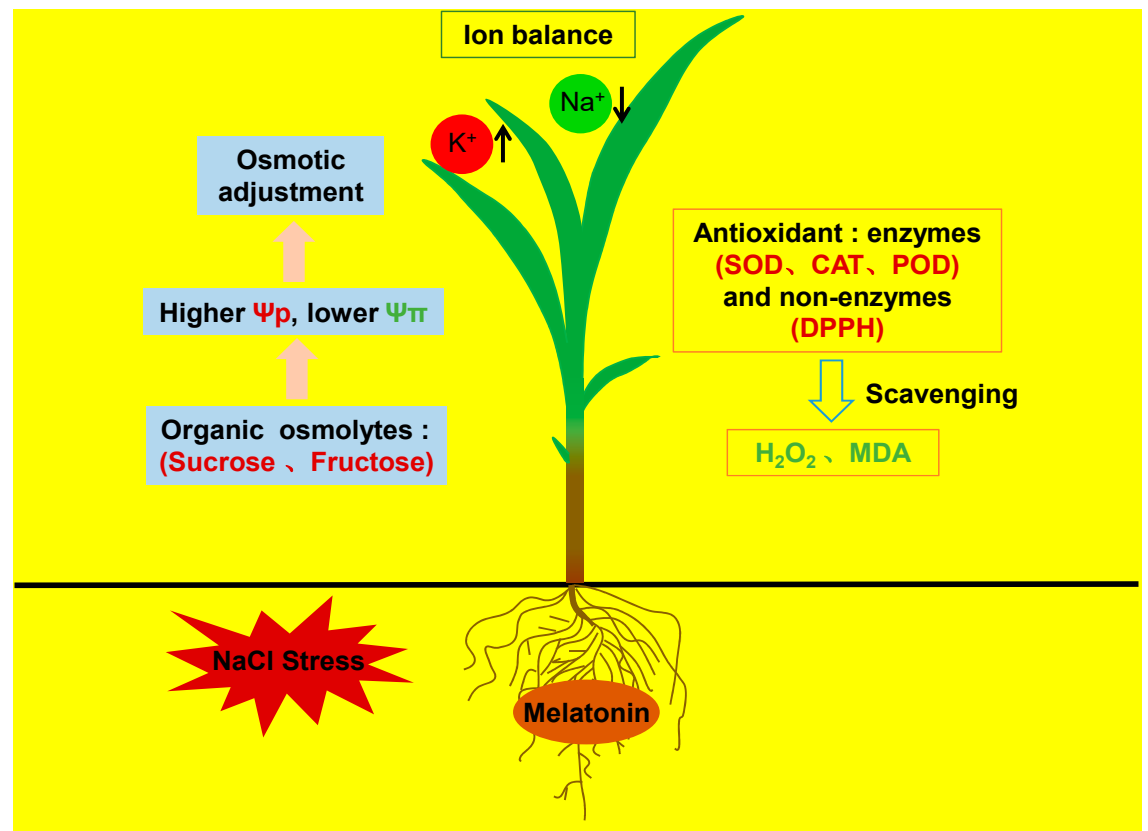

Figure 9. Schematic model showing the role of exogenous melatonin on improving the salt tolerance in maize: Exogenous melatonin application enhanced maize salt tolerance in three ways: osmotic adjustment (accumulated sucrose and fructose), ion balance (maintained a higher $\mathrm{K}^{+} / \mathrm{Na}^{+}$), and alleviation of salt-induced oxidative stress (activated antioxidative enzymes and nonenzymatic antioxidant).

Author Contributions: Conceived and designed the experiments, S.W. and L.Y.; provided guidance in whole experimental process, X.D.; performed the experiment and analyzed the date, J.R., J.Y., and G.L. All authors have read and agreed to the published version of the manuscript.

Funding: This research was supported by the National Key Technology Research and Development Program (No.2018YFD1001000), the 111 project of the Chinese Education Ministry (B12007), and the Special-Fund of Scientific Research Programs of State Key Laboratory of Soil Erosion and Dryland Farming on the Loess Plateau (A314021403-C5).

Conflicts of Interest: The authors declare no conflict of interest.

\section{References}

1. Arnao, M.B.; Hernández-Ruiz, J. Melatonin: A new plant hormone and/or a plant master regulator? Trends Plant. Sci. 2018, 24, 38-48. [CrossRef]

2. Chen, Y.E.; Mao, J.J.; Sun, L.Q.; Huang, B.; Ding, C.B.; Gu, Y.; Liao, J.Q.; Hu, C.; Zhang, Z.W.; Yuan, S. Exogenous melatonin enhances salt stress tolerance in maize seedlings by improving antioxidant and photosynthetic capacity. Physiol. Plantarum 2018, 164, 349-363. [CrossRef]

3. Wang, P.; Sun, X.; Li, C.; Wei, Z.; Liang, D.; Ma, F. Long-term exogenous application of melatonin delays drought-induced leaf senescence in apple. J. Pineal Res. 2013, 54, 292-302. [CrossRef]

4. Zhang, N.; Sun, Q.; Zhang, H.; Cao, Y.; Weeda, S.; Ren, S.; Guo, Y.D. Roles of melatonin in abiotic stress resistance in plants. J. Exp. Bot. 2015, 66, 647. [CrossRef] [PubMed]

5. Kaya, A.; Doganlar, Z.B. Melatonin improves the multiple stress tolerance in pepper (Capsicum annuum). Sci. Hortic. 2019, 256. [CrossRef]

6. Li, X.; Wei, J.P.; Scott, E.R.; Liu, J.W.; Guo, S.; Li, Y.; Zhang, L.; Han, W.Y. Exogenous melatonin alleviates cold stress by promoting antioxidant defense and redox homeostasis in camellia sinensis L. Molecules 2018, 23, 165. [CrossRef] [PubMed]

7. Qiao, Y.; Yin, L.; Wang, B.; Ke, Q.; Deng, X.; Wang, S. Melatonin promotes plant growth by increasing nitrogen uptake and assimilation under nitrogen deficient condition in winter wheat. Plant. Physiol. Bioch. 2019, 139, 342-349. [CrossRef] 
8. Wang, M.; Duan, S.; Zhou, Z.; Chen, S.; Wang, D. Foliar spraying of melatonin confers cadmium tolerance in Nicotiana tabacum L. Ecotox. Environ. Safe. 2019, 170, 68-76. [CrossRef]

9. Wei, Z.; Li, C.; Gao, T.; Zhang, Z.; Liang, B.; Lv, Z.; Zou, Y.; Ma, F. Melatonin increases the performance of Malus hupehensis after UV-B exposure. Plant. Physiol. Bioch. 2019, 139, 630-641. [CrossRef]

10. Arora, D.; Bhatla, S.C. Melatonin and nitric oxide regulate sunflower seedling growth under salt stress accompanying differential expression of $\mathrm{Cu} / \mathrm{Zn}$ SOD and Mn SOD. Free Radic. Biol. Med. 2017, 106, 315-328. [CrossRef]

11. Hwang, O.J.; Back, K. Melatonin deficiency confers tolerance to multiple abiotic stresses in rice via decreased brassinosteroid levels. Int. J. Mol. Sci. 2019, 20, 5173. [CrossRef] [PubMed]

12. Li, X.; Yu, B.; Cui, Y.; Yin, Y. Melatonin application confers enhanced salt tolerance by regulating $\mathrm{Na}^{+}$and $\mathrm{Cl}^{-}$accumulation in rice. Plant. Growth Regul. 2017, 83, 1-14. [CrossRef]

13. Wang, L.Y.; Liu, J.L.; Wang, W.X.; Sun, Y. Exogenous melatonin improves growth and photosynthetic capacity of cucumber under salinity-induced stress. Photosynthetica 2016, 54, 19-27. [CrossRef]

14. Wei, W.; Li, Q.T.; Chu, Y.N.; Reiter, R.J.; Yu, X.M.; Zhu, D.H.; Zhang, W.K.; Ma, B.; Lin, Q.; Zhang, J.S. Melatonin enhances plant growth and abiotic stress tolerance in soybean plants. J. Exp. Bot. 2015, 66, 695. [CrossRef] [PubMed]

15. Zhou, X.; Zhao, H.; Cao, K.; Hu, L.; Du, T.; Baluška, F.; Zou, Z. Beneficial roles of melatonin on redox regulation of photosynthetic electron transport and synthesis of D1 protein in tomato seedlings under salt stress. Front. Plant. Sci. 2016, 7, 1823. [CrossRef]

16. Jiang, C.; Cui, Q.; Feng, K.; Xu, D.; Li, C.; Zheng, Q. Melatonin improves antioxidant capacity and ion homeostasis and enhances salt tolerance in maize seedlings. Acta Physiol. Plant. 2016, 38, 1-9. [CrossRef]

17. Li, H.; Chang, J.; Chen, H.; Wang, Z.; Gu, X.; Wei, C.; Zhang, Y.; Ma, J.; Yang, J.; Zhang, X. Exogenous melatonin confers salt stress tolerance to watermelon by improving photosynthesis and redox homeostasis. Front. Plant. Sci. 2017, 8, 295. [CrossRef]

18. Liang, C.; Zheng, G.; Li, W.; Wang, Y.; Hu, B.; Wang, H.; Wu, H.; Qian, Y.; Zhu, X.G.; Tan, D.X. Melatonin delays leaf senescence and enhances salt stress tolerance in rice. J. Pineal Res. 2015, 59, 91-101. [CrossRef]

19. Zhang, H.J.; Zhang, N.; Yang, R.C.; Wang, L.; Sun, Q.Q.; Li, D.B.; Cao, Y.Y.; Weeda, S.; Zhao, B.; Ren, S. Melatonin promotes seed germination under high salinity by regulating antioxidant systems, ABA and $\mathrm{GA}_{4}$ interaction in cucumber (Cucumis sativus L.). J. Pineal Res. 2015, 57, 269-279. [CrossRef]

20. Ke, Q.; Ye, J.; Wang, B.; Ren, J.; Yin, L.; Deng, X.; Wang, S. Melatonin mitigates salt stress in wheat seedlings by modulating polyamine metabolism. Front. Plant. Sci. 2018, 9, 914. [CrossRef]

21. Dąbrowski, P.; Kalaji, M.H.; Baczewska, A.H.; Pawluśkiewicz, B.; Mastalerczuk, G.; Borawska-Jarmułowicz, B.; Paunov, M.; Goltsev, V. Delayed chlorophyll a fluorescence, MR 820, and gas exchange changes in perennial ryegrass under salt stress. J. Lumin. 2017, 183, 322-333. [CrossRef]

22. Kalaji, H.M.; Govindjee; Bosa, K.; Kościelniak, J.; Żuk-Gołaszewska, K. Effects of salt stress on photosystem II efficiency and $\mathrm{CO}_{2}$ assimilation of two Syrian barley landraces. Environ. Exp. Bot. 2011, 73, 64-72. [CrossRef]

23. Munns, R.; Tester, M. Mechanisms of salinity tolerance. Annu. Rev. Plant. Biol. 2008, 59, 651. [CrossRef]

24. Chen, D.; Yin, L.; Deng, X.; Wang, S. Silicon increases salt tolerance by influencing the two-phase growth response to salinity in wheat (Triticum aestivum L.). Acta Physiol. Plant. 2014, 36, 2531-2535. [CrossRef]

25. Yin, L.; Wang, S.; Tanaka, K.; Oka, M. Application of silicon improves salt tolerance through ameliorating osmotic and ionic stresses in the seedling of Sorghum bicolor. Acta Physiol. Plant. 2013, 35, 3099-3107. [CrossRef]

26. Kostopoulou, Z.; Therios, I.; Roumeliotis, E.; Kanellis, A.K.; Molassiotis, A. Melatonin combined with ascorbic acid provides salt adaptation in Citrus aurantium L. seedlings. Plant Physiol. Bioch. 2015, 86, 155-165. [CrossRef]

27. Wang, A.Y.; Li, Y.; Zhang, C.Q. QTL mapping for stay-green in maize (Zea mays). Can. J. Plant. Sci. 2012, 92, 249-256. [CrossRef]

28. Bates, L.S.; Waldren, R.P.; Teare, I.D. Rapid determination of free proline for water-stress studies. Plant. Soil 1973, 39, 205-207. [CrossRef]

29. Storey, R. Salt tolerance, ion relations and the effect of root medium on the response of citruos to salinity. Aust. J. Plant. Physiol. 1995, 22, 101-114. 
30. Loreto, F.; Velikova, V. Isoprene produced by leaves protects the photosynthetic apparatus against ozone damage, quenches ozone products, and reduces lipid peroxidation of cellular membranes. Plant. Physiol. 2001, 127, 1781-1787. [CrossRef]

31. Heath, R.L.; Packer, L. Photoperoxidation in isolated chloroplasts. I. Kinetics and stoichiometry of fatty acid peroxidation. Arch. Biochem. Biophysic. 1968, 125, 189-198. [CrossRef]

32. Beauchamp, C.O.; Fridovich, I. Isozymes of superoxide dismutase from wheat germ. BBA-Protein Structure 1973, 317, 50-64. [CrossRef]

33. Hamurcu, M.; Sekmen, A.H.; Turkan, İ.; Gezgin, S.; Demiral, T. Induced anti-oxidant activity in soybean alleviates oxidative stress under moderate boron toxicity. Plant. Growth Regul. 2013, 70, 217-226. [CrossRef]

34. Kochba, J.; Lavee, S.; Spiegelroy, P. Differences in peroxidase activity and isoenzymes in embryogenic ane non-embryogenic 'Shamouti' orange ovular callus lines. Plant. Cell Physiol. 1977, 18, 463-467. [CrossRef]

35. Wang, S.; Xie, B.; Yin, L.; Duan, L.; Li, Z.; Eneji, A.E.; Tsuji, W.; Tsunekawa, A. Increased UV-B radiation affects the viability, reactive oxygen species accumulation and antioxidant enzyme activities in maize (Zea mays L.) pollen. Photochem. Photobiol. 2010, 86, 110-116. [CrossRef]

36. Byeon, Y.; Back, K. Melatonin synthesis in rice seedlings in vivo is enhanced at high temperatures and under dark conditions due to increased serotonin $\mathrm{N}$-acetyltransferase and $\mathrm{N}$-acetylserotonin methyltransferase activities. J. Pineal Res. 2014, 56, 189-195. [CrossRef] [PubMed]

37. Zhang, N.; Zhao, B.; Zhang, H.J.; Weeda, S.; Yang, C.; Yang, Z.C.; Ren, S.; Guo, Y.D. Melatonin promotes water-stress tolerance, lateral root formation, and seed germination in cucumber (Cucumis sativus L.). J. Pineal Res. 2012, 54, 15-23. [CrossRef]

38. Volkmar, K.M.; Hu, Y.; Steppuhn, H. Physiological responses of plants to salinity: A review. Can. J. Plant. Sci. 1998, 78, 19-27. [CrossRef]

39. Ye, J.; Wang, S.; Deng, X.; Yin, L.; Xiong, B.; Wang, X. Melatonin increased maize (Zea mays L.) seedling drought tolerance by alleviating drought-induced photosynthetic inhibition and oxidative damage. Acta Physiol. Plant. 2016, 38, 1-13. [CrossRef]

40. Su, X.; Fan, X.; Shao, R.; Guo, J.; Wang, Y.; Yang, J.; Guo, L. Physiological and iTRAQ-based proteomic analyses reveal that melatonin alleviates oxidative damage in maize leaves exposed to drought stress. Plant. Physiol. Bioch. 2019, 142, 263-274. [CrossRef]

41. Yang, C.; Chong, J.; Li, C.; Kim, C.; Shi, D.; Wang, D. Osmotic adjustment and ion balance traits of an alkali resistant halophyte Kochia sieversiana during adaptation to salt and alkali conditions. Plant. Soil 2007, 294, 263-276. [CrossRef]

42. Lee, G.; Carrow, R.N.; Duncan, R.R.; Eiteman, M.A.; Rieger, M.W. Synthesis of organic osmolytes and salt tolerance mechanisms in Paspalum vaginatum. Environ. Exp. Bot. 2008, 63, 19-27. [CrossRef]

43. Shi, H.; Qian, Y.; Tan, D.X.; Reiter, R.J.; He, C. Melatonin induces the transcripts of CBF/DREB1s and their involvement in both abiotic and biotic stresses in Arabidopsis. J. Pineal Res. 2015, 59, 334. [CrossRef] [PubMed]

44. Kishor, P.; Hong, Z.; Miao, G.H.; Hu, C.; Verma, D. Overexpression of [delta]-pyrroline-5-carboxylate synthetase increases proline production and confers osmotolerance in transgenic plants. Plant. Physiol. 1995, 108, 1387-1394. [CrossRef]

45. Ashraf, M.; Foolad, M.R. Roles of glycine betaine and proline in improving plant abiotic stress resistance. Environ. Exp. Bot. 2007, 59, 206-216. [CrossRef]

46. Madan, S.; Nainawatee, H.S.; Jain, R.K.; Chowdhury, J.B. Proline and proline metabolising enzymes in in-vitro selected nacl-tolerant brassica junceal L. under salt stress. Ann. Bot. 1995, 76, 51-57. [CrossRef]

47. Nayyar, H.; Walia, D.P. Water stress induced proline accumulation in contrasting wheat genotypes as affected by calcium and abscisic acid. Biol. Plantarum 2003, 46, 275-279. [CrossRef]

48. Lacerda, C.F.D.; Cambraia, J.; Oliva, M.A.; Ruiz, H.A.; Prisco, J.T.N. Solute accumulation and distribution during shoot and leaf development in two sorghum genotypes under salt stress. Environ. Exp. Bot. 2003, 49, 107-120. [CrossRef]

49. Lutts, S.; Majerus, V.; Kinet, J.M. NaCl effects on proline metabolism in rice (Oryza sativa) seedlings. Physiol. Plantarum 2010, 105, 450-458. [CrossRef]

50. Zhu, J.K. Regulation of ion homeostasis under salt stress. Curr. Opin. in Plant. Biol. 2003, 6, 441-445. [CrossRef] 
51. Shabala, S.; Cuin, T.A. Potassium transport and plant salt tolerance. Physiol. Plantarum 2008, 133, 651-669. [CrossRef] [PubMed]

52. Li, C.; Wang, P.; Wei, Z.; Liang, D.; Liu, C.; Yin, L.; Jia, D.; Fu, M.; Ma, F. The mitigation effects of exogenous melatonin on salinity-induced stress in Malus hupehensis. J. Pineal Res. 2012, 53, 298-306. [CrossRef] [PubMed]

53. Zhao, G.; Zhao, Y.; Yu, X.; Kiprotich, F.; Han, H.; Guan, R.; Shen, W. Nitric oxide is required for melatonin-enhanced tolerance against salinity stress in rapeseed (Brassica napus L.) seedlings. Int. J. Mol. Sci. 2018, 19, 1912. [CrossRef]

54. Li, C.; Liang, B.; Chang, C.; Wei, Z.; Zhou, S.; Ma, F. Exogenous melatonin improved potassium content in Malus under different stress conditions. J. Pineal Res. 2016, 61, 218-229. [CrossRef]

55. Foyer, C.H.; Noctor, G. Tansley. Oxygen processing in photosynthesis: Regulation and signalling. New Phytol. 2010, 146, 359-388. [CrossRef]

56. Meng, J.F.; Xu, T.F.; Wang, Z.Z.; Fang, Y.L.; Xi, Z.M.; Zhang, Z.W. The ameliorative effects of exogenous melatonin on grape cuttings under water-deficient stress: Antioxidant metabolites, leaf anatomy, and chloroplast morphology. J. Pineal Res. 2015, 57, 200-212. [CrossRef]

57. Zhao, H.; Ye, L.; Wang, Y.; Zhou, X.; Yang, J.; Wang, J.; Cao, K.; Zou, Z. Melatonin increases the chilling tolerance of chloroplast in cucumber seedlings by regulating photosynthetic electron flux and the ascorbate-glutathione cycle. Front. Plant. Sci. 2016, 7, 1814. [CrossRef]

58. Tan, D.X.; Hardeland, R.; Manchester, L.C.; Korkmaz, A.; Ma, S.; Rosales-Corral, S.; Reiter, R.J. Functional roles of melatonin in plants, and perspectives in nutritional and agricultural science. J. Exp. Bot. 2012, 63, 577-597. [CrossRef]

59. Shi, H.; Chan, Z. The cysteine2/histidine2-type transcription factor ZINC FINGER OF ARABIDOPSIS THALIANA 6-activated C-REPEAT-BINDING FACTOR pathway is essential for melatonin-mediated freezing stress resistance in Arabidopsis. J. Pineal Res. 2014, 57, 185-191. [CrossRef]

(C) 2020 by the authors. Licensee MDPI, Basel, Switzerland. This article is an open access article distributed under the terms and conditions of the Creative Commons Attribution (CC BY) license (http://creativecommons.org/licenses/by/4.0/). 